\title{
Effect of Surgery on Quality of Life with Operable Breast Cancer in Limited Resource Environments: Reply
}

\author{
Alida F. W. van der Steeg • Jolanda De Vries • \\ Jan A. Roukema
}

Published online: 26 October 2010

(c) The Author(s) 2010. This article is published with open access at Springerlink.com

We thank Purvi Thakkar et al. for their comments on our article [1]. It is good to see that our results are reproducible. The reported decrease in quality of life may be explained by the fact that a different questionnaire was used. The FACT-B is a disease-specific questionnaire that inquires more into functioning than into satisfaction with functioning.

The primary goal of our study was to present surgeons with other factors than only the clinical parameters, such as tumor size, that can help in the decisional process. We hope that more surgeons will assess the personality of a woman with early-stage breast cancer and use this as additional information when counseling her about possible breast cancer treatment modalities.

\footnotetext{
A. F. W. van der Steeg $(\bowtie) \cdot$ J. A. Roukema Department of Surgery, St. Elisabeth Hospital, P.O. Box 90151, 5000 LC Tilburg, The Netherlands

e-mail: A.F.vanderSteeg@amc.uva.nl

J. De Vries · J. A. Roukema

Department of Psychology and Health, Medical Psychology,

Tilburg University, P.O. Box 90153, 5000 LE Tilburg,

The Netherlands

A. F. W. van der Steeg

Pediatric Surgical Center Amsterdam, Emma Children's

Hospital, AMC and VU University Medical Center,

P.O. Box 22660, 1100 DD Amsterdam, The Netherlands

A. F. W. van der Steeg - J. De Vries - J. A. Roukema CoRPS, Center of Research on Psychology in Somatic diseases,

Tilburg University, Tilburg, The Netherlands
}

Open Access This article is distributed under the terms of the Creative Commons Attribution Noncommercial License which permits any noncommercial use, distribution, and reproduction in any medium, provided the original author(s) and source are credited.

\section{References}

1. van der Steeg AF, De Vries J, Roukema JA (2010) Anxious personality and breast cancer: possible negative impact on quality of life after breast-conserving therapy. World J Surg 34(7): $1453-1460$ 